\title{
Relaparotomy : Analysis of 50 Cases And Review of Literature
}

\author{
Prabhu Singh*, Rajveer arya, Ashok kumar mathur and Jeevan kankaria \\ Sawai Man Singh Medical College and Hospital, India
}

Submission: March 03, 2017; Published: March 20, 2017

*Corresponding author: Prabhu singh, Sawai Man Singh Medical College and Hospital ,Jaipur JLN marg - Jaipur, India, Tel: 07897240453; Email: drprabhusswami@gmail.com

\begin{abstract}
Introduction: Reoperative Abdominal Surgery (Relaparotomy) means an unplanned reintervention carried out during the immediate postoperative period after laparotomy and causally related to first operation.

Method: The study had been carried out in upgraded department of General Surgery in SMS Medical College and Hospital. The cases comprises of operated in SMS Hospital and those referred from other surgical centers.

Results: Maximum patients $70 \%$ needs relaparotomy only one time which had minimum mortality (11.4\%). Four patients (8\%) were needed relaparotomy 3 times in which 2 patient were expired. Mean while mortality rate of 3rd relaparotomy was $50 \%$. Relaparotomy were done mainly for adhesion obstruction and anastomotic leakage. Adhesion obstruction superwanes anastomotic leakage (40\% v/s $28 \%) .4 \%$ patients in which foreign body (sponge in peritoneal cavity at the time of previous surgery) were found both cases operated for caesarian section. $68 \%$ patients were refered from some other institution
\end{abstract}

Conclusion: Decision to perform relaparotomy as per patients condition, if taken in time it can improv overall survival and have a positive impact on decrease length of hospital stay, overall cost of treatment and morbidity as well as mortality.

\section{Introduction}

Reoperative Abdominal Surgery (Relaparotomy) means an unplanned reintervention carried out during the immediate postoperative period after laparotomy and causally related to first operation. In practice laparotomy and relaparotomy as thus defined are performed with few exceptions during the same stay in hospital [1-13]. Relaparotomy is carried out for wide range of indications. The highest incidence is seen in gastrointestinal surgery and the lowest in vascular surgery. Main Indications are:
A. Haemorrhage
B. Ileus
C. Paritonitis
i. Disruption of anastomoses and infection.
ii. Residual intra peritoneal abscess
iii. Fistulae
D. Acute postoperative adhesion obstruction
E. Multiple system failure
F. Miscellaneous indications

Relaparotomy carries very high morbidity and mortality. Mortality range varies from 40 to $45 \%$ as mentioned in various studies [4,11]. Relaparotomy for dehiscence and obstruction carried minimal risk; for bleeding and infection entailed moderate risks; and for anastomotic leak have highest mortality rate. The mortality rate increased in older age groups, multiple system and organ failure and multiple relaparotomies. Timely relaparotomy is valuable in the identification and treatment of complications following abdominal surgery.

The literature on relaparotomy is confusing. The incidence and mortality rates are greately affected by the type of surgery reported. There also a difference between recent and older studies with regard to definitions and indications for relaparotomy, rendering comparisions of these studies rather useless [11]. With the advent of newer antibiotics, better management of fluid and electrolyte imbalance and latest investigations particularly contrast CT Scan abdomen and MRI, surgeons are able to diagnose the problem after first laparotomy in most cases which helps to better management of these cases. Whether these antibiotic, investigations and other things have improved the morbidity and mortality in patients undergoing relaparotomy will also be studied. 


\section{Aims and Objectives}

Analysis of cases of relaparotomy regarding indications, the organ of primary operations, age of patients to analyse incidence, morbidity and mortality and other factors.

To study the importance of technique and other error at primary operation and benefits gain from relaparotomy.

To know whether timing of relaparotomy has effect on morbidity and mortality.

\section{Materials and Methods}

The study had been carried out in upgraded department of General Surgery in SMS Medical College and Hospital. The cases comprise of operated in SMS Hospital and those referred from other surgical centers. Detailed history and examination were recorded in performs with special note on original operation or procedure attempted previously. Presentation of patient in immediate postoperative period or delayed postoperative period were noted. A battery of investigations including various routine and special blood investigation, USG and other radiological investigations were done. CT Scan, MRI were undertaken as per requirement. The detailed finding of relaparotomy was noted. Patient were monitored postoperatively and progress of patient were assessed and any immediate or delayed postoperative complications were recorded.

\section{Inclusion Criteria}

Patients more than 12 years of age who underwent laparotomy for various indications and needed reexploration for dealing the complications.

\section{Exclusion Criteria}

i. Patients below 12 years of age.

ii. Patients operated for Hernia.

iii. Patients who required minor surgical procedures and operations on abdominal wall.

iv. Cases of abdominal wound dehiscence.

v. Stoma closure i.e. Ileostomy and Colostomy

\section{Results}

Table 1: Age wise distribution of relaparotomy patients.

\begin{tabular}{|c|c|c|}
\hline Age & No. of Cases & $\%$ \\
\hline $12-20$ & 3 & 6 \\
\hline $21-30$ & 4 & 17 \\
\hline $31-40$ & 10 & 20 \\
\hline $41-50$ & 16 & 32 \\
\hline
\end{tabular}

\begin{tabular}{|c|c|c|}
\hline $51-60$ & 10 & 22 \\
\hline$>60$ & 4 & 10 \\
\hline Total & 50 & $100 \%$ \\
\hline
\end{tabular}

As given in Table 1, In our study most of cases (52\%) were in the age group 31-50yrs. 16 cases (32\%) were adults in forth decade.
i. Age range
ii. lowest-12yrs
iii. highest-75yrs
iv. Mean age -41
v. $\quad$ Mean deviation $=2.02$
vi. Maximum cases (52\%) were re-explored within 2-7 days.

Most of the patient in this category were anastomotic leakage , heamorrhage, perforation repair in which anastomotic leakage was outnumbered.

\section{I. $\quad$ Mean time gap $=11.27$}

Maximum patients $70 \%$ needs relaparotomy only one time which had minimum mortality (11.4\%). Four patients (8\%) were needed relaparotomy 3 times in which 2 patient were expired. Mean while mortality rate of 3 rd relaparotomy was $50 \%$.

Relaparotomy were done mainly for adhesion obstruction and anastomotic leakage. Adhesion obstruction superwanes anastomotic leakage ( $40 \% \mathrm{v} / \mathrm{s} 28 \%) .4 \%$ patients in which foreign body (sponge in peritoneal cavity at the time of previous surgery) were found both cases operated for caesarian section. $68 \%$ patients were refered from some other institution.

\section{A. Referred case :}
a. $\quad$ Mean -4.8
b. Mean deviation - 3.55
c. Standard deviation -4.22

\section{B. Our Institution case :}
a. Mean - 2.29
b. $\quad$ Mean deviation -2.12
c. Standard deviation -2.49

I. The average duration of intestinal obstruction was 7.2, ranging from 2-42 days. Causes of intestinal obstruction may be either ileus, or adhesion obstruction etc.

II. The average duration of peritonitis after primary surgery was 7.2. 
III. Bleeding has minimum time lag (ie 2.1 mean days)

IV. 25 patients $(83.33 \%)$ recovered when operated within $<10$ days duration while 5 patients $(16.7 \%)$ were expired.

V. The mortality rate was maximum in those patients where time interval was in between 11-42 days. 4 patient out of 15 (26.66), as compared to those where time interval was $<10$ days. 5 patient out of $30(16.66 \%)$.

VI. Case fatality rate (CFR) was minimum where Relaparotomy was performed within 10 days.

VII. Adhesion as a cause of relaparotomy was maximum in case where primary surgery was undertaken as exploratory laparotomy within unknown added. procedure.

VIII. In cases where primary surgery was done for intestinal obstruction, peritonitis as a cause of relaparotomy areas maximum cases.

IX. In $40 \%$ cases adhesionolysis were done with or without associated ileostomy or feeding jejunostomy.

X. $10 \%$ patients needs exteriorization of loop in such circumstances where resection anastomosis was not possible.

XI. Multiple adhesion were outnumbered as compared to single band adhesion. The ratio of multiple verses single band adhesion was $4: 1$ (16/4 cases).
a. $\quad$ Mean - 10.7
b. $\quad$ Mean deviation -4.81
c. $\quad$ Standard deviation -5.33

XII. In 54\% cases there was no apparent error found that was responsible for cause of relaparotomy.

XIII. We found technical error in approx 12\% cases and in $34 \%$ cases presumptive error was found. As a complication of relaparotomy maximum case having wound infection was observed (44\%) approximately half of them proceeds into wound dehiscence or burst abdomen.10 patients or relaparotomies were expired, thus morality rate observed in our studies was $20 \%$.

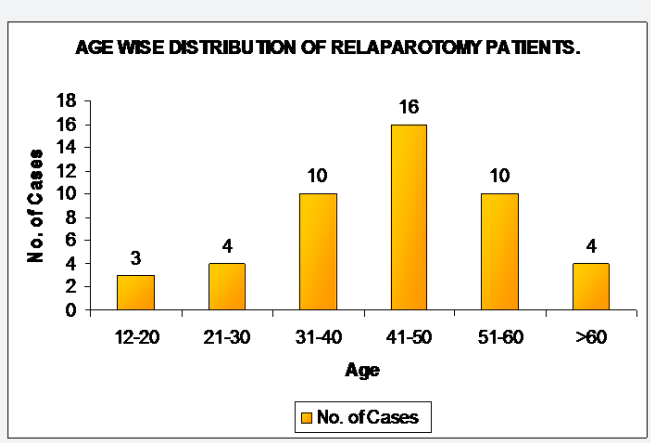

Figure 1: Graph of Institution.

XIV. 4 cases $(40 \%)$ were expired due to sepsis and septicaemic shock (Figures 1-6).
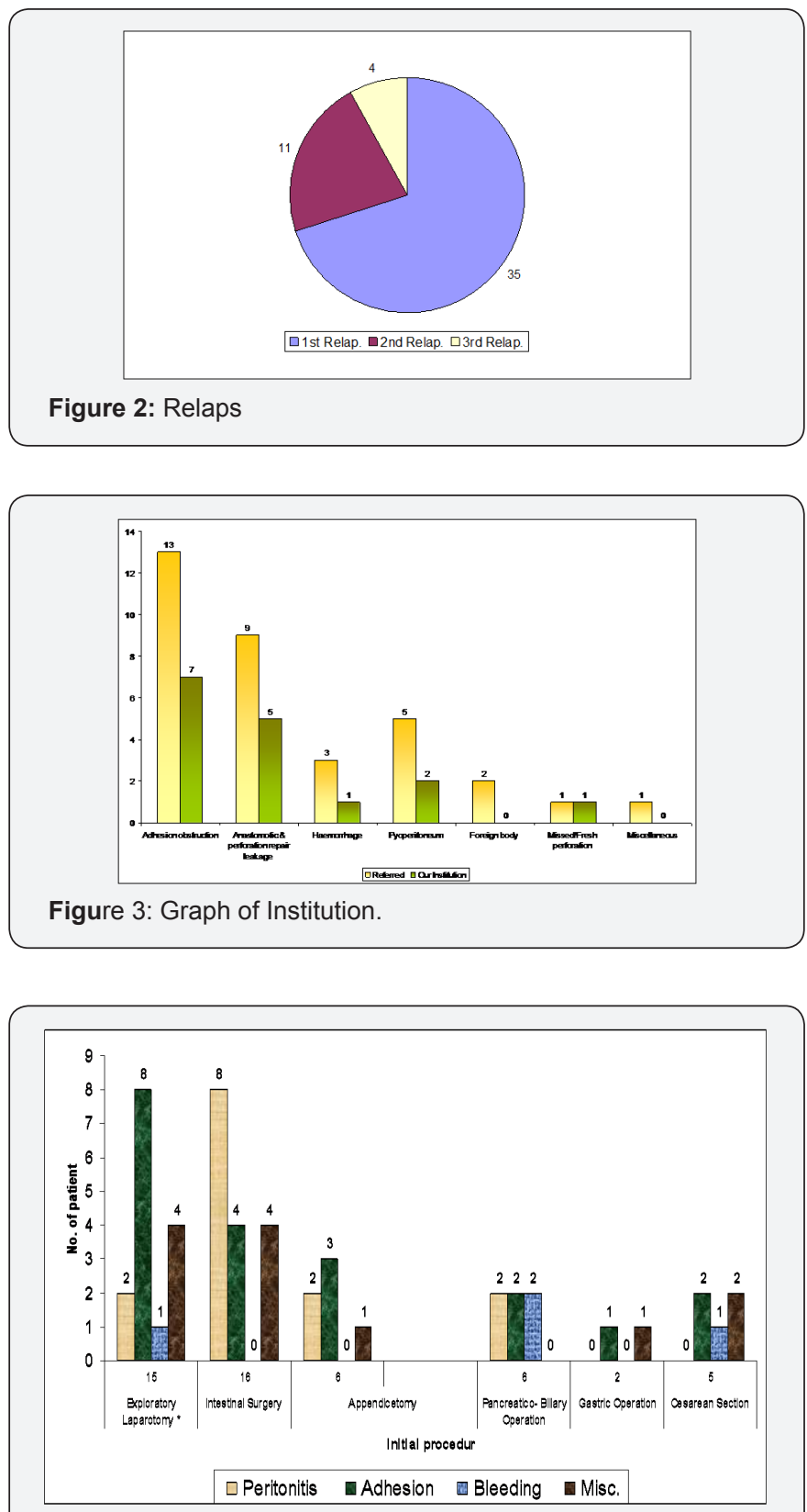

Figure 4: Graphical View.

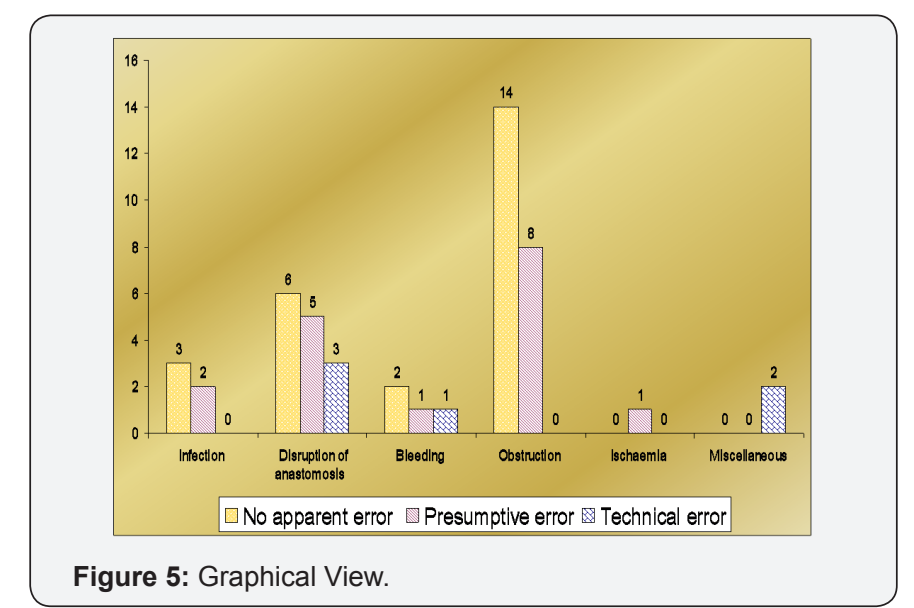




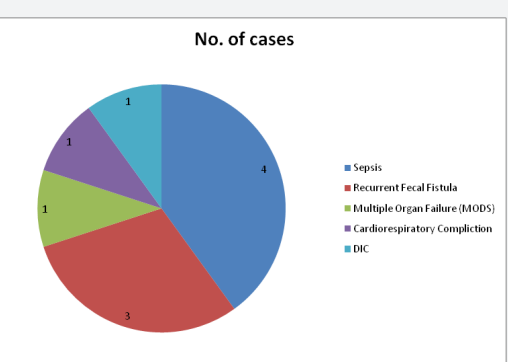

Figure 6: No. of cases.

\section{Discussion and Conclusion}

In our study most of cases (52\%) were in the age group 31-50yrs. 16 cases (32\%) were adults in forth decade. Maximum cases (52\%) were re-explored within 2-7 days. Most of the patient in this category were anastomotic leakage, heamorrhage, perforation repair in which anastomotic leakage was outnumbered. Mean time gap was 11.27 days. Maximum patients $70 \%$ needs relaparotomy only one time which had minimum mortality (11.4\%). Four patients (8\%) were needed relaparotomy 3 times in which 2 patient were expired. Mean while mortality rate of 3 rd relaparotomy was $50 \%$. Relaparotomy were done mainly for adhesion obstruction and anastomotic leakage. Adhesion obstruction superwanes anastomotic leakage (40\% v/s 28\%). 4\% patients in which foreign body (sponge in peritoneal cavity at the time of previous surgery) were found both cases operated for caesarian section. $68 \%$ patients were refered from some other institution.

Table 2:Distribution of cases as per time gap in relaparotomy from initial procedure.

\begin{tabular}{|c|c|c|}
\hline Cases Re Exp. & No. of Cases & \% \\
\hline within 48 hrs & 11 & 22 \\
\hline Within 2-7 days & 26 & 52 \\
\hline$>7$ days & 13 & 26 \\
\hline $41-50$ & 16 & 32 \\
\hline
\end{tabular}

Table 3:Distribution of cases as per numbers of relaparotomy

\begin{tabular}{|c|c|c|}
\hline & No. & \% \\
\hline 1st Relap. & 35 & 70 \\
\hline 2nd Relap. & 11 & 22 \\
\hline
\end{tabular}

\begin{tabular}{|c|c|c|}
\hline 3rd Relap. & 4 & 8 \\
\hline $41-50$ & 16 & 32 \\
\hline
\end{tabular}

Table 4:Distribution of cases as per the reason for relaparotomy.

\begin{tabular}{|c|c|c|c|}
\hline Disease & Referred & $\begin{array}{c}\text { Our } \\
\text { Institution }\end{array}$ & Total \\
\hline $\begin{array}{c}\text { Adhesion } \\
\text { obstruction }\end{array}$ & 13 & 7 & 20 \\
\hline $\begin{array}{c}\text { Anastomotic } \\
\text { \& perforation } \\
\text { repair leakage }\end{array}$ & 9 & 5 & 14 \\
\hline Haemorrhage & 3 & 1 & 4 \\
\hline $\begin{array}{c}\text { Pyoperitoneum } \\
\text { Foreign body }\end{array}$ & 5 & 0 & 2 \\
\hline Missed/Fresh \\
perforation
\end{tabular}

Table 5:The time lag in arising complications that warrents replaparotomy.

\begin{tabular}{|c|c|c|}
\hline \multirow{2}{*}{ Complications } & \multicolumn{2}{|c|}{ Day of onset of complication } \\
\cline { 2 - 3 } & Range (days) & $\begin{array}{c}\text { Average } \\
\text { (mean days) }\end{array}$ \\
\hline Obstruction & $2-42$ & 7.2 \\
\hline Peritonitis & $1-14$ & 5.2 \\
\hline Bleeding & $1-3$ & 2.1 \\
\hline Pyoperitoneum & $2-15$ & 6.7 \\
\hline Miscellaneous & $1-15$ & 9.2 \\
\hline
\end{tabular}

Table 6:Effect of timing of surgical intervention on results.

\begin{tabular}{|c|c|c|c|}
\hline $\begin{array}{c}\text { Time Interval between } \\
\text { primary surgery and } \\
\text { relaparotomy }\end{array}$ & Recovery & Expired & CFR \\
\hline $\begin{array}{c}<10 \text { days. } \\
(\mathrm{n}=30)\end{array}$ & 25 & 5 & $16.7 \%$ \\
\hline $11-42$ days & 11 & 4 & $26.7 \%$ \\
$(\mathrm{n}=15)$ & 4 & 1 & $20.0 \%$ \\
\hline$>42$ days & & & \\
\hline
\end{tabular}


Table 7: Correlation between the initial operations and the type of complication.

\begin{tabular}{|c|c|c|c|c|c|c|}
\hline \multirow[t]{2}{*}{ initial procedure } & \multirow[t]{2}{*}{ No. of patient } & \multicolumn{4}{|c|}{ Complication Requiring Relaparotomy } & \multirow[t]{2}{*}{$\begin{array}{c}\text { Chi-square } \\
\text { Test }\end{array}$} \\
\hline & & Peritonitis & Adhesion & Bleeding & Misc. & \\
\hline $\begin{array}{l}\text { Exploratory } \\
\text { Laparotomy* }\end{array}$ & 15 & 2 & 8 & 1 & 4 & $\begin{array}{c}\mathrm{X}^{2}=10.22 \\
\mathrm{df}=3 \\
\mathrm{p}=0.021\end{array}$ \\
\hline Intestinal Surgery & 16 & 8 & 4 & - & 4 & $\begin{array}{c}X^{2}=3 \\
d f=2 \\
p=0.273\end{array}$ \\
\hline Appendicetomy & 6 & 2 & 3 & - & 1 & $\begin{array}{c}X^{2}=1.5 \\
d f=2 \\
p=0.472\end{array}$ \\
\hline $\begin{array}{c}\text { Pancreatico- } \\
\text { Biliary Operation }\end{array}$ & 6 & 2 & 2 & 2 & - & $\begin{array}{c}\mathrm{X}^{2}=0 \\
\mathrm{df}=2 \\
\mathrm{p}=1\end{array}$ \\
\hline Gastric Operation & 2 & - & 1 & - & 1 & - \\
\hline Cesarean Section & 5 & - & 2 & 1 & 2 & $\begin{array}{c}X^{2}=0.6 \\
d f=2 \\
p=0.741\end{array}$ \\
\hline Total & 50 & 14 & 20 & 4 & 12 & $\begin{array}{c}X^{2}=13.973 \\
d f=3 \\
p=0.004\end{array}$ \\
\hline
\end{tabular}

Table 8: Operative procedure conducted.

\begin{tabular}{|c|c|c|}
\hline & Number & \% \\
\hline Adhesionolysis & 20 & 40 \\
\hline Perforation repair & 6 & 12 \\
\hline Drainage & 11 & 22 \\
\hline $\begin{array}{c}\text { Resection } \\
\text { anastomosis }\end{array}$ & 8 & 16 \\
\hline $\begin{array}{c}\text { Exteriorization of } \\
\text { loop }\end{array}$ & 4 & 10 \\
\hline $\begin{array}{c}\text { Ileostomy } \\
\text { Feeding jejunostomy }\end{array}$ & 18 & 36 \\
\hline
\end{tabular}

In $40 \%$ cases adhesionolysis were done with or without associated ileostomy or feeding jejunostomy. 10\% patients need exteriorization of loop in such circumstances where resection anastomosis was not possible. Multiple adhesions were outnumbered as compared to single band adhesion. The ratio of multiple verses single band adhesion was $4: 1(16 / 4$ cases). In $54 \%$ cases there was no apparent error found that was responsible for cause of relaparotomy (Tables 2-8). We found technical error in approx $12 \%$ cases and in $34 \%$ cases presumptive error was found. As a complication of relaparotomy maximum case having wound infection was observed (44\%) approximately half of them proceeds into wound dehiscence or burst abdomen. 10 patients or relaparotomies were expired, thus morality rate observed in our studies was $20 \% .4$ cases $(40 \%)$ were expired due to sepsis and septicaemic shock.

\section{Review of Literature}

Harry Tera Curt Aberg, Sweden [14]. Relaparotomy is a serious reality for every abdominal surgeon. Elderly patients are at greater risk and have a grave prognosis. Complications that carried out high mortality are namely wound rupture after colon surgery and suture breakdown with peritonitis following gastric surgery. These facts should be kept in mind throughout every routine laparotomy and at every stage of operation surgeon should remain wide awake to the risk of complication that may require relaparotomy [12]. Michael Zer, Shlomo Dux [15]. did a study regarding timing of laparotomy and its influence on prognosis. Lorenc and Driver favour early reoperation and state that such patients have far more to gain than to lose by reexploration [13]. Lorenc admitted that fear of an unfavourable outcome led to undue postponement of reintervention in many cases of postoperative complications and he recommended that early re intervention be adopted as a policy of choice.

James GH Bernard MJ, New York (1983), did a study and concluded that most common finding during relaparotomy was intra-abdominal abscess, other finding included anastomotic leak, necrotic bowel, evidence of technical errors and acalculous cholecystitis. The most common clinical finding were localised 
tenderness, fever and absent bowel sound. CT Scan and contrast radiography were most accurate. Harbrecht PJ, Garrison RN Fry DE [4]. Intervals from laparotomy to relaparotomy varied widely with the indications. These were relatively brief intervals from laparotomy to relaparotomy for bleeding and long intervals to relaparotomy for obstructions. Relaparotomy for infections with intact organs caused the most complex problems.

Rudolph Krause [12]. Factors that appear to correlate with mortality are age over more than 50 years peritonisis at initial procedures and multiple system failure. Criteria leading to relaparotomy are usually clinical (tenderness, fever, and absence of bowel sounds) and to a minor extent depending onn radiological procedures of which computed tomographics scanning has the highest accuracy (97\%), multiple system failure carries the highest mortality rate $(80 \%$, if treated) and presents the greatest number of negative laparotomies [11]. RM Kirk [10]. Royal Free Hospital, London (1988) The decision to reoperate was based on clinical findings in $97.8 \%$ although investigations were often helpful in localizing the site of the complicating lesion. Leaks and bleeding were most frequent and carried a high mertality.

Makela J and Kairaluoma M I [14]. Relaparotomy for postoperative intra-abdominal sepsis in jaundiced patients.. Postoperative sepsis was caused by intra-abdominal abscess in 16 cases ( 53 per cent), by suture line leakage in 9 cases (30 per cent) and by technical error in 5 cases (17 per cent). Abscesses occurred most commonly in the subphrenic space (6 cases), in the subhepatic space ( 6 cases) and in the lesser sac ( 5 cases). Sepsis was associated with single organ failure in 20 cases and with multiple organ failure in 10 cases. The overall mortality rate was 50 per cent $(15 / 30)$.

Pickleman J, Lee RM [8]. Non operative management should be tried in every patients with suspected early postoperative small bowel obstruction unless clear signs of bowel ischemia are present. A nasogastric tube will provide adequate decompression and total parenteral nutrition should be instituted. If the patient remain stable, this treatment should be continued for 2 weeks [14-39]. After this time further improvement is unlikely and reexploration should be performed unless there are clinical or radiological signs of relenting obstruction. D I KrivitskiÄV A ShuliarenkoI A Babin [9]. 10,446 patients were operated on. There were the following indications for relaparotomy: diffuse and circumscribed peritonitis (78 patients), ileus (46), eventration (11), hemorrhage (12), others (5). Diagnosis of postoperative complications requiring relaparotomy is difficult. The postoperative was $26 \%$.

AR Mossa, David M, Bruce S [1]. They did a study regarding iatrogenic bile duct injuries and mention factors contributing it namely. Dangerous disease (convalescence from acute cholecystitis or with portal hypertension) Dangerous anatomy (anomalies in 10-15\% cases). Dangerous surgery (most common cause) [1]. Zavernyi LG, Poida, Me AI VM, Bondarenko ND, Tarasov AA, et al. [13]. The analysis and processing with the use of a special method of 54 direct observations and 342 case records of the patients with early postoperative intraabdominal complications were carried out. A method for syndrome prediction of the outcomes of relaparotomy has been developed [40-43]. The syndromes of the most significant predictive value have been revealed: those of intoxication, respiratory and hepatorenal failure, impaired hemodynamics and electrolytic metabolism, hemocoagulation. Use in clinical practice of the method mentioned as well as the methods promoting timely detection of the intraabdominal complications permitted to reduce lethality after relaparotomy from 21.4 to $15.3 \%$.

Haut Ohmann, Wolmeshauser, Wacha, Qun yang wittmann, H Dellinger e, et al. [43]. Planned relaparotomy was defined as at least one relaparotomy decided on at the time of the first surgical intervention ; RD, relaparotomy indicated by clinical findings. There was no significant difference in mortality between patients treated with PR (21\%) or RD (13\%). Postoperative multiple organ failure as defined by a Goris score of more than 5 was more frequent in the group of patients undergoing PR (50\%), compared with the group undergoing RD (24\%) $(\mathrm{P}=.01)$, as were infectious complications (68\% vs $39 \%$ [P=.01]). Infectious complications were due to more frequent suture leaks (16\% vs $0 \%[\mathrm{P}=.05])$, recurrent intra-abdominal sepsis ( $16 \%$ vs $0 \%[\mathrm{P}=.05])$, and septecemia ( $45 \%$ vs $18 \%[\mathrm{P}=.05]$ ) in the PR vs the RD groups. They Concluded that until larger prospective studies are available, the indication for PR should be evaluated with caution (Tables $9 \& 10$ ).

Table 9: Error at primary laparotomy in 50 relaparotomies.

\begin{tabular}{|c|c|c|c|}
\hline $\begin{array}{c}\text { Indication for } \\
\text { relaparotomy }\end{array}$ & $\begin{array}{c}\text { No apparent } \\
\text { error }\end{array}$ & $\begin{array}{c}\text { Presumptive } \\
\text { error }\end{array}$ & $\begin{array}{c}\text { Technical } \\
\text { error }\end{array}$ \\
\hline Infection & 3 & 2 & - \\
\hline $\begin{array}{c}\text { Disruption of } \\
\text { anastomosis }\end{array}$ & 6 & 5 & 3 \\
\hline Bleeding & 2 & 1 & 1 \\
\hline Obstruction & 14 & 8 & - \\
\hline Ischaemia & - & 1 & - \\
\hline Miscellaneous & - & - & 6 \\
\hline Total & 27 & 17 & 2 \\
\hline
\end{tabular}

Table 10: Complication after relaparotomy.

\begin{tabular}{|c|c|c|}
\hline Complication & No. of cases & \% \\
\hline $\begin{array}{c}\text { Respiratory } \\
\text { complication }\end{array}$ & 20 & 40 \\
\hline eg. ARDS, PE & 22 & 44 \\
\hline Wound infection & 10 & 20 \\
\hline $\begin{array}{c}\text { Wound dehiscence / } \\
\text { Burst abdomen }\end{array}$ & 3 & 6 \\
\hline $\begin{array}{c}\text { Ileostomy related } \\
\text { complication }\end{array}$ & 6 & 12 \\
\hline DVT &
\end{tabular}




\begin{tabular}{|c|c|c|}
\hline Uraemia (ARF) & 4 & 8 \\
\hline UTI & 4 & 8 \\
\hline Miscellaneous & 3 & 6 \\
\hline
\end{tabular}

Koerna T, Schulz F [18]. Relaparotomy in peritonitis,prognosis and treatment of patients with persisting intraabdominal infection.some patients are prone to persisting intraabdominal infection regardless of initial eradication of the source of infection. There was no significant difference in the postoperative mortality rate between "planned relaparotomy" and "relaparotomy on demand"(54.5\% versus 50.6\%).Timely relaparotomy provides the only surgical option that significantly improves outcome. To improve overall survival the decision to perform a relaparotomy on demand after an initially successful eradication of the source of ,infection must be made within $48 \mathrm{hr}$,at least before MODS emerges.

Lamme B, Boermeester MA, Reitsma J B, Mahler CW, Obertop H, Gouma DJ [32]. The combined results of observational studies showed a statistically non-significant reduction in mortality for the on-demand relaparotomy strategy compared with the planned relaparotomy strategy. However, owing to the nonrandomised nature of the studies, the limited number of patients per study and the heterogeneity between studies, the overall results were inconclusive. VJ verwaal, Academisch Ziekenhuis, St Radboud, Nijmegen, The Netherlands [33]. 46 patients with abdominal sepsis were treated. The diagnosis of abdominal sepsis was defined as meeting the Bone criteria for sepsis before operation, in combination with infection of the abdomen proven by laparotomy. After the first laparotomy there were 41 relaparotomies in these 46 patients. From 2 days before to 3 days after the relaparotomy, data were collected to compile the Acute Physiology and Chronic Health Evaluation (APACHE) III and Multiple Organ Failure (MOF) scores. The scores were compared before and after relaparotomy, and were also compared between patients who had a recurrent infection in the abdomen and those who did not.

Table 11: Mortality rate.

\begin{tabular}{|c|c|}
\hline Cause & No. of Cases \\
\hline Sepsis & 4 \\
\hline Recurrent fecal fistula & 3 \\
\hline MODS & 1 \\
\hline Cardiopulmonary complication & 1 \\
\hline DIC & 1 \\
\hline Total & 10 \\
\hline
\end{tabular}

During 41 relaparotomies, 16 patients were found to have a pus collection. Of these clinical infections only 11 had a positive culture. In patients with clinical infection there was also no difference pre and post operative. The same applied for patients with and without positive intraabdominal cultures. Relaparotomy in patients with abdominal sepsis did not have a negative effect on prognosis within a few days after reoperation.
The authors did not find any reason to use APACHE III or MOF scoring as an indication for relaparotomy (Table 11).

Exposito EM, Argon PF, Curbelo PR, Perez AJ [34]. The group of AA remained constituted of 25 patients with an average age of 46 years and with an APACHE II score of $20.63 \pm 3.24$. The group of the programmed relaparotomies (RP) was conformed of 35 patients whose average age was 52 years and APACHE II score, $22.85 \pm 5.68$. Intestinal fistula was observed in three patients $(12 \%)$ of the AA group and the abdominal compartment syndrome in two patient $(5.7 \%)$ of the RP group. Five $(20 \%)$ abdominal wall hernias were found in patients of the AA group, while only one patient in the RP group (2.8\%) had a hernia [4450]. They found significant differences between both groups utilizing mortality as variable of grouping. We think that early diagnosis of intraabdominal sepsis continues as the fundamental beginning to diminish mortality of the patients with acute peritonitis independent of the surgical technique utilized, the capacity of the administered antibiotics, and the solvency of support care.

Hilzheimer RG, Gathof B [17]. Relaparotomy for complicated secondary peritonitis-how to identify patients at risk for persistent sepsis. N Hiki, Y Takeshita, K Kubota, E Tsuji, H Yamaguchi, et al. [38]. Postoperative small bowel obstruction following abdominal procedures is more common in patients who have undergone laparotomy The typical winter weather in Tokyo is characterised by low temperatures, low humidity and moderate air pressure. These winter climate conditions could be correlated with an increased incidence of postoperative small bowel obstruction in during our observation period.

Jonas Dauderys,Donatas Venskutonis [45]. Relaparotomy must be motivated, timely, and must certainly remove cause of the complication. Formalion of feeding microjejunostomy should be a component of the relaparotomy. In case of diffuse peritonitis a repeated programmed relaparotomies nowdays are not advisable. Hutchins RR,Gunning MP,Lucas DN [19]. Relaparotomy may be beneficial in patients developing intraperitoneal sepsis after abdominal procedures.They also assessed the effect of patient age \&sex, disease presentation and severity, interval to relaparotomy, and the number of relaparotomies on survival after relaparotomy. Patient age and multiorgan failure prior to relaparotomy-but not urgency of initial laparotomy or the acute physiology and chronic health evaluation (APACHE ll) score prior to relaparotomy, interval to relaparotomy,or number of relaparotomies-affected the outcome. The identification of intraperitoneal sepsis and performance of relaparotomy earlier after the initial abdominal surgery might reduce the high rrate $(60 \%)$ of multiorgan failure prior to relaparotomy and improve survival after it.

Elie oussltouzoglou, pillippe bacheliar, Jean marc bigourden, Hiroshi nakano [39]. The overall relaparotomy rate was significantly lower in the PG group (4.7\%) than in the PJ group 
(18\%; $\mathrm{P}=.001)$. The rate of relaparotomy required to treat complications of PF after PD was 52.9\% (9/17) in the PJ group. In the PG group, none of the 4 patients who developed PF required relaparotomy. Martínez-Ordaz JL, Suárez-Moreno RM, FelipezAguilar OJ, Blanco-Benavides R [27]. To assess the mortality related factors of patients after relaparotomy on demand. In some patients, a relaparotomy after a primary laparotomy is necessary, most due to acute complications. The relaparotomy can be planned or on demand based on the evolution of the patient.Of 51 relaparotomies, $98 \%$ were positive. Nineteen of the 33 patients died, resulting in a mortality rate of $58 \%$. The factors associated with mortality were development of an intestinal fistula ( $p<0.02$ ), wound infection ( $p<0.03$ ), generalized peritonitis in the primary surgery ( $p<<0.001)$, urgent primary laparotomy ( $p<0.003$ ), development of multiple organ failure $(p<0.005)$, and respiratory insufficiency $(p<0.01)$. Conclusions: Laparotomy on demand is useful in the treatment of patients with abdominal sepsis; however, the mortality is still very high.

Unalp HR, Kamer E, Kar H, Bal A,Peskersoy M [22]. Treatment of a number of complications that occur after abdominal surgeries may require that urgent abdominal Re-explorations (UAR) ,the life saving and obligatory operations are performed. UARs that are perfomed following complicated abdominal have high mortality rates. In particular, UARs have higher mortality rates following GIS surgeries or when infectious complications occur.The possibility of efficiently lowering these high rates depends on the success of the first operations that the patient had received. Neil Hyman, Thomas LM, Turner 0 [7]. More than half of leaks can be managed without fecal diversion. Anastomotic disruption is perhaps the most dreaded complication after intestinal surgery.

Ruler, van o,Lamme B, Gouma DJ, Reitsma JB, Boermeester [26]. The decision whether and when to perform a relaparotomy in secondary peritonitis is largely subjective and based on professional experience. No exiting scoring system aids in this decisional process.One preoperative predictor and five postoperative predictors significantly increased the need of relaparotomy.

i. Younger age

ii. Decreased hemoglobin levels,

iii. Temperature $>39$ degrees $\mathrm{C}$

iv. Lower Pao(2)/Fio2 ratio,

v. Increased heart rate

vi. Increased sodium levels.

Causes of secondary peritonitis and finding at emergency laparotomy for peritonitis are poor indicators for whether patients will need a relaparotomy. Factors indicative of progressive or persistent organ failure during arly postoperative follow-up are the best indicators for ongoing infection and associated positive findings at relaparotomy.
Jean-Jacques Duron, Nathalie Jourdan-Da Silva, Sophie Tezenas du Montcel, Anne Berger, Fabrice Muscari, et al. [35]. Postoperative intraperitoneal adhesions, or bands, resulting from any type of abdominal surgery, are the main cause of adhesive postoperative small bowel obstructions, which represent a life-long issue. Recurrences after operated adhesive postoperative SBO are a threatening potentiality for patients and a difficult problem facing any surgeon. Operated adhesive postoperative SBO is a clinical entity with a high recurrence rate and specific risk factors of recurrences. Thus, the patients operated on for adhesive postoperative SBO may be candidates for the preventive use of anti-adhesion agents, particularly when a risk factor of recurrence is present.

Opening the peritoneal cavity, in whatever type of surgery, leads to the formation of potentially obstructive structures (adhesions or bands) in almost $95 \%$ of patients. Today, with the increased incidence of abdominal surgery, these structures are the most frequent cause of small bowel obstruction (SBO). Since 1990, it has been reported that adhesive SBO occurs in $3 \%$ of all laparotomies, $1 \%$ during the first postoperative year. After operated adhesive postoperative SBO, a risk of recurrence remains and the literature reported a wide ranging rate of overall recurrence (range, 8.7\%-53\%) at 3 years and more. These variations may be due to the retrospective type of the studies.

Today, operated adhesive postoperative SBO proves to be a clinical entity with high incidence and specific risk factors of recurrence: age $<40$ years, presence of adhesion or matted adhesion, and postoperative surgical complications. These results render patients undergoing operated adhesive postoperative SBO candidates for the preventive use of antiadhesion agents, particularly when a risk factor of recurrence is present. JBC Vander wal, J Jeekel [6]. Postoperative adhesion formation is the most frequent complication of surgery. With the incidence of 55 to $100 \%$ in all abdominal operations adhesions are responsible for and increased risk of small bowel obstraction, chronic abdominal pain and infertility. Statins may play a role in postoperative adhesion prevention.

Acute adhesive obstruction of the small intestine is a surgical Emergency In which there is risk of intestinal strangulation. By delaying diagnosis and institution of appropriate treatment for strangulated obstruction, morbidity and mortality from sepsis are greatly increased in comparison to simple obstruction. Postoperatively most common cause of SBO is peritoneal adhesions.In particular colorectal, surgery is noted of the largest offeders, especially after proctocolectomy and ileal pouch anal aastomosis. Pelvic or lower abdominal procedures are blamed for adhesion formation more commonly than upper abdominal proceduresare, although any abdominal operation can be responsible. They result in an inflammatory cascade involving the activation of complement and coagulation. Fibrinogen is produced during this response and converted to fibrin by thrombin. If fibrin persists,it adheres to injured 
surfaces and initiates the formation of a matrix of collagen and fibroblasts,thereby forming fibrous adhesions from fibrinous adhesions.

\section{Prevention}

i. Technical efforts much as gentle tissue handling ,minimal use of foreign materials, careful haemostatic measures, and prevention of infection,ischemia, and desication.

ii. Substences including amniotic fluid, bovine cecum, shark peritoneum, fish bladder, vitreous of calfs eye, lubricants ,gels,polymers, and various physical barriers.

iii. Sodium hyaluronate-based bioresorbable membrane,seprafilm, which persists in the abdomen for 5 to 7 days [6].

Doeksen A, Tanis PJ, Vrouenraets BC, Lanschot van JJ, Tets van WF [25]. An intervening weekend and negative diagnostic imaging reports may contribute to a delay in diagnosis and relaparotomy for anastomotic leakage. That delay was more than two days in two-thirds of the patients. Oddeke vR,cecilia WM, Kimberly RB [20]. In patients with severe secondary peritonitis, there are 2 surgical treatment strategies following an initial emergency laparotomy; planned relaparotomy and relaparotomy only when the patients condition demands it.The on demand strategy may reduce mortality, morbidity,health care utilization, and costs.But not have a significantly lower rate of death or major peritonitis -related morbidity.

SealSL,Kamilya G,BhattacharyyaSK,MukherjiJ,Bhattacharyya AR [31]. Repeat laparotomy within 6 weeks of cesarean delivery was required following 1 in 300 cases done in an Indian teaching hospital. The majority of these were preventable and could have been avoided if adequate attention had been paid at the time of the primary surgery. Christian Nordqvist [48]. Rather than carrying out repeat surgery for patients with severe intraabdominal inflammation or infection (peritonitis) routinely, it might be better to just have the repeat surgery when clinical improvement is lacking. Secondary peritonitis has a death rate of between $20 \%-60 \%$, patients stay in hospital for a long time and also are much more likely to experience illness due to the development of sepsis with multiple organ failure.

About $12 \%-16 \%$ of patients who choose to undergo abdominal surgery develop post-operative peritonitis. Health care utilization due to secondary peritonitis is extensive, with operations to eliminate the source of infection (laparotomy [surgery involving the intra-abdominal contents]) and multidisciplinary care in the intensive care unit setting." The writers also point out that after the initial laparotomy, relaparotomy may be needed to eliminate persistent peritonitis or new infections. "There are 2 widely used relaparotomy strategies: relaparotomy when the patient's condition demands it ('on-demand') and planned relaparotomy. In the planned strategy, a relaparotomy is performed every 36 to 48 hours for inspection, drainage, and peritoneal lavage [flushing out] of the abdominal cavity until findings are negative for ongoing peritonitis. Judith Groch, Robert Jasmer [41]. In severe peritonitis, repeat laparotomy done only when the patient's condition demands it cuts down on the number of procedures and on medical costs, researchers found.

\section{Action Points}

A. Explain to interested patients that doing a repeat laparotomy after emergency surgery for severe peritonitis is common.

B. Explain that sometimes it's done on a preplanned schedule - every 36 to 48 hours - and sometimes it's done only when the patient's condition demands it.

C. Note that both strategies have about the same morbidity and mortality, but that the "on demand" tactic may reduce the number of repeat procedures and the medical costs.

On-demand relaparotomy did not reduce mortality or morbidity. Patients had severe secondary peritonitis and an Acute Physiology and Chronic Health Evaluation (APACHEII) score of 11 or greater. A key challenge for an on-demand strategy is to adequately select patients for relaparotomy and to prevent potential harmful delay in reintervention by adequate and frequent patient monitoring, the researchers suggested. One of the difficulties in research on secondary peritonitis is the heterogeneity of the study population, regarding severity of disease, etiology, and localization of the infectious focus. These factors make it difficult to extrapolate study results to individual patients in clinical practice. For this reason, the researchers said, they excluded disease entities, such as pancreatitis, with a substantially different prognosis and requiring different treatment strategies, they wrote $[41,42]$.

Lombardovaillant,TomásAriel; FernandezExposito,Wilfredo Y Casamayor Jaime, Zuleika [49]. Relaparotomy on demand is a proper procedure for peritonitis of moderate intensity, whereas the scheduled procedure is adequate for patients with severe peritonitis and uncertain intestinal viability. The first postoperative week had the highest incidence on adverse events and required more surveillance. Alexander R Novotny, Klaus Emmanuel, Norbert Hueser, Carolin Knebel, Monika Kriner, et al. [46]. On-demand relaparotomy has been associated with a slightly decreased mortality compared to planned relaparotomy in the surgical treatment of secondary peritonitis. On-demand relaparotomy must be performed without delay to detect progressing sepsis early, before the onset of multiorgan failure. The PCT ratio appears to be a valuable aid in deciding if further relaparotomies are necessary after initial operative treatment of an intraabdominal septic focus.

Brain A Nobie [36]. A small-bowel obstruction (SBO) is caused by a variety of pathologic processes. The leading cause 
of SBO in developed countries is postoperative adhesions (60\%) followed by malignancy, Crohn's disease, and hernias, although some studies have reported Crohn disease as a greater etiologic factor than neoplasia. Surgeries most closely associated with SBO are appendectomy, colorectal surgery, and gynecologic and upper gastrointestinal (GI) procedures. One study from Canada reported a higher frequency of SBO after colorectal surgery, followed by gynecologic surgery, hernia repair, and appendectomy. Lower abdominal and pelvic surgeries lead to obstruction more often than upper GI surgeries.

\section{Causes}

I. The most common cause of $\mathrm{SBO}$ is postsurgical adhesions.

II. Postoperative adhesions can be the cause of acute obstruction within 4 weeks of surgery or of chronic obstruction decades later.

III. The incidence of SBO parallels the increasing number of laparotomies performed in developing countries.

IV. The second most common identified cause of SBO is an incarcerated groin hernia.

V. Other etiologies of SBO include malignant tumor (20\%), hernia (10\%), inflammatory bowel disease (5\%), volvulus (3\%), and miscellaneous causes (2\%).

VI. The causes of SBO in pediatric patients include congenital atresia, pyloric stenosis, and intussusception [36].

Martinez-Casas I, Sancho JJ, Nve E, Pons MJ, Membrilla E, Grande L [50]. Advanced age, the presence of either fever or hypothermia, and the need of mechanical ventilation are preoperative risk factors associated with mortality after relaparotomy and should be considered when planning reintervention. Karen Brasel, MD, Morad Hameed, MD, Michael Sarr [30]. Patients in the on-demand group did not have significantly lower mortality or major peritonitis-related morbidity than those in the planned relaparotomy group, but did have fewer relaparotomies and a substantial reduction in health care utilization and medical costs.

Diaa M El-Mowafi, Michael P Diamond [37]. Adhesions, usually secondary to previous surgical procedures, are the most common cause of intestinal obstructions in the United States, and are responsible for $49 \%$ to $74 \%$ of small bowel obstruction in industrial countries. As adhesion formation remains an unavoidable event, so the need for adjuvants for its prevention was called for. A multitude of agents with different mechanism of action have been developed, investigated and tried. Unfortunately, none of them proved its absolute effectiveness in prevention of postsurgical adhesions or getting a universal acceptance from surgeons. Classes of Adhesion-reduction adjuvants and their proposed mechanism of action
I. Fibrinolytic agents (fibrinolysis, stimulation of plasminogen activators)
a. Fibrinolysin
b. Streptokinase
c. Urokinase
d. Hyaluronidase
e. Chymotrypsin
f. Trypsin
g. Pepsin
h. Plasminogen activators
II. Anticoagulants (prevention of clot and fibrin formation)
a. Heparin
b. Citrates
c. Oxalates

III. Anti-inflammatory Agents (reduce vascular permeability, reduce histamine release, stabilize lysozomes)
a. Corticosteroids
b. Nonsteroidal anti-inflammatory agents
c. Anti-histamines
d. Progesterone
e. Calcium channel blockers
f. Colchicine
IV. Antibiotics (prevent infection)
a. Tetracyclines
b. Cephalosporins

V. Mechanical Separation (surface separation, hydroflotation)
a. Intra-abdominal instillates:
b. Crystalloid solutions
c. Dextran
d. Mineral oil
e. Silicone
f. Vaseline
g. Carboxymethylcllulose
h. Hyaloronic acid
i. Chelated hyaluronic acid
j. Barriers: 
k. Endogenous tissues:

l. Omental grafts

m. Peritoneal grafts

n. Bladder strips

o. Fetal membranes

p. Exogenous materials:

q. Fibrin glue

r. Polytetrafluoroethylene

s. Oxidized cellulose

t. Oxidized regenerated cellulose

u. Gelatin

v. Rubber sheets

w. Metal foils

x. Plastic hoods

y. Modified hyaluronic acid \& CMC

z. Poloxamer 407

aa. Repel

The most commonly investigated and used agents are fibrinolytics, anticoagulants, anti-inflammatory agents, antibiotics, and mechanical separating agents. Fibrinolytic agents act directly by reducing the fibrinous mass and indirectly by stimulating plasminogen activator activity.81 These agents were promising in some animal studies.82.83 and frustrating in others,84 while it was even associated with hemorrhagic complication85 and impairment of wound healing86 in another reports. Heparin is the most widely investigated anticoagulant for the purpose of prevention of adhesions.

Anti-inflammatory agents were used to reduce the initial inflammartory response to tissue injury and hence, subsequent adhesion formation. Most of the animal studies showed the effectiveness of non-steroidal anti-inflammatory drugs (NSAIDs) in prevention of adhesions. In spite of that, other studies failed to prove any beneficial effect of intramuscular or intraperitoneal administration of ibuprofen in reduction of preitoneal adhesions in rat and rabbit models.94,95 Unfortunately, no clinical trials with NSAIDs have been published up until now, although, several have been conducted.

The rationale behind the use of antibiotics is prophylaxis against infection, and hence the inflammatory response, that leads to adhesion development. Cephalosporines and tetracyclin98 were among the widely used drugs for this purpose. Unfortunately, there are no well-designed clinical trial supporting this. Postoperative adhesions are among the commonest causes of intestinal obstruction. The latter is a very serious condition, potentially exposing the patient to bowel perforation, peritonitis, and death within few hours in a considerable percentage of cases. Early diagnosis and treatment of these patients is the key to saving their life. Meticulous adherence to the surgical principles for adhesion reduction, as well as the use of adjuvants created for this purpose can be of great help to decrease the incidence of subsequent postsurgical adhesions, and hopefully bowel obstruction [37].

Brent CO, Kimberly RB, Van R, Johannes BR [23]. The reduction in societal costs renders the on-demand strategy amore efficient relaparotomy tsrategr in patients with sever peritonitis.these differences were found across the full range of health -care resources as well as across patients with different courses of disease. Planned relaparotomy consistently generated more costs across the whole range of different courses of disease.

Katherine Mandell and Saman Arbabi [29]. The role of relaparotomy in the management of intra-abdominal infection remains controversial. Two strategies have been used: Planned re-laparotomy or laparotomy on demand. Although in the past, planned re-laparotomy made sense for ensuring source control, improvements in imaging, intensive care therapy, and percutaneous interventions may have shifted the balance toward the laparotomy-on-demand strategy. Regardless of strategy, the rate of negative laparotomy remains high $(>30 \%)$. Randomized trials are not available to provide definitive evidence, and clinical judgment continues to be the basis for decision making. Further work to develop more specific clinical tools and criteria to improve the accuracy of diagnosis may lead to use of the laparotomy-on-demand strategy rather than planned relaparotomy. At this time, there is no good clinical evidence to support one strategy over the other from a mortality standpoint.

Ospedale S. Giovanni Bosco [40]. Laparotomy performed for both emergency of elective surgery may by complicated by intrabdominal collection, anastomotic leakage, infarction and others. This conditions are able to induce peritoneal inflammation. Inflamed peritoneum are able to produce excess of lactate that we can measure by collecting fluid from peritoneal drainage. Drainage were left in abdomen for monitoring intrabdominal condition until the passage of stool or flatus. Minimum drainage of serum is present daily also in uncomplicated post operative period.

Serum lactate relates with increased systemic anaerobic metabolism such as SIRS, sepsis and systemic hypoperfusion and it is easy to measure with a blood gas analysis. The decision whether and when to perform a relaparotomy in secondary peritonitis is largely subjective and based on professional experience. Actually no existing scoring system aids in this decision. Post operative intraabdominal sepsis due to surgical complications is associated with an important mortality and morbidity. Early diagnosis is crucial to improve outcome. Relaparotomy could be necessary to eradicate the intraabdominal 
focus of sepsis or hypoperfusion. The relaparotomy must be performed early after the diagnosis of surgical complications before the onset of multi organ failure Park CE, Sung JE, Kyung MS, Cho Y, Ro ES [47].

\section{Conclusion}

In most cases, bleeding controls for intractable bleeding after postpartum hysterectomy were successful during and after relaparotomy in spite of development of dilutional coagulopthy due to massive transfusion, and resulted in rapid recovery and good prognosis. Even though dilutional coagulopthy was developed because of massive transfusion, relaparotomy was safe and effective procedure for management of intractable hemorrhage after emergency postpartum hysterectomy with clotting factor replacement. If personnel and adequate clotting factor replacement are available, relaparotomy should not be delayed for management of intractable hemorrhage and unstable vital sign after emergency postpartum hysterectomy.

\section{References}

1. AR Moossa, A David Mayer, Bruce S (1990) Iatrogenic Injury to the Bile Duct. Arch Surg 125(8): 1028-1030.

2. Driver T, Kelly G, Eiseman B (1978) Reoperation after Abdominal Trauma. Am J Surg 135(6): 747-750.

3. Freddy M, Pennickx Raymond PK, Peter ML (1983) Planned Relaparotomies in the Surgical Treatment of Severe Generalized Peritonitis from Intestinal Origin. World J Surg 7(6): 762-766.

4. Harbrecht PJ, Garrison RN, Fry DE (1984) Early urgent relaparotomy. Arch Surg 119(4): 369-374.

5. Hinsdale JG, Jaffe BM (1984) Re-operation for intra-abdominal sepsis. Ann Surg 199(1): 31-36.

6. JBC Vander Wal, J Jeekel (2007) The use of Statins in Postoperative Adhesion Prevention.

7. Neil Hyman, Thomas LM, Turner O, Besty B, Peter C (2006) Anastomotic leaks after intestinal anastomosis, Vermont, Burlington.

8. Pickleman J, Robert M Lee (1989) The Management of Patients with Suspected early. Postoperative small bowel obstraction.

9. D Krivitskiä, V Shuliarenko, I Babin (1990) Indications for relaparotomy. Khir (1):18-21

10. RM Kirk (1988) Reoperative Surgery for early complications following abdominal and abdominothoracic operations. J R Soc Med 81(1): 7-9.

11. Roche J (1981) Effectiveness of computed tomography in the diagnosis of intra-abdominal abscess. A review of 111 patients. Med J Aust 2(2): 87-88.

12. Rudolph Krause, Reintervention in abdominal surgery, Word J. Surg. 11:226-232, 1987.

13. Zavernyi LG, Poida AI, Mel?ik VM, Bondarenko ND, Tarasov AA, Nadeev SS, Stepanik VIa ,Prognosis in the outcome of relaparotomy iKln Khir. 1992;(8):12-6.

14. Tera H, Aberg C (1975) Relaparotomy. A ten-year series. Acta Chir Scand 141(17): 637-644.

15. Zer M, Dux S, Dintsman M (1980) The timing of relaparotomy and its influence on prognosis. Am J Surg 139(3): 338-343.

16. van Goor H, Hulsebos RG, Bleichrodt RP (1997) Complications of planned relaparotomy in patients with severe general peritonitis. European J surg 163(1): 61-66.

17. Holzheimer RG, Gathof B (2003) Reoperation for complicated secondary peritonitis -how to identify patient at risk for persist sepsis. Eur J Med Res 8(3): 125-134.

18. Koperna T, Schulz F (2000) Relaparotomy in peritonitis; prognosis and treatment of patient with persisting intraabdominal infection. World J Surg 24(1): 32-37.

19. Hutchins RR, Gunning MP, Lucas DN,Allen-Mersh TG, Soni NC (2004) Relaparotomy for suspected intraperitoneal sepsis after abdominal surgery. World J Surg 28(2): 137-141.

20. van Ruler O, Mahler CW, Boer KR, Reuland EA, Gooszen HG, et al. (2007) Comparision of On-Demand vs Planned Relaparotomy strategy in patients with severe peritonitis. JAMA 298(8): 865-872.

21. Ching SS, Murlikrishnan VP, Whiteley GS (2003) Relaparotomy: a five -year review of indication and outcome. Int J Clin Pract 57(4): 333-337.

22. Unalp HR, Kamer E, Kar H, Bal A, Peskersoy M (2006) Urgent abdominal re-explorations.World J Emerg Surg 4: 1:10.

23. Brent CO, Kimberly RB, Oddeke VR, Johannes BR, Hein G, et al. (2010) Cost of relaparotomy on-demand versus planned relaparotomy in patients with severe peritonitis; an economic evaluation within a RCT. Critical care 14: r97.

24. Ingrid JM Han-Geurts, Cornelis Verhoef, Hugo W (2004) Tilanus Relaparotomy following Complications of Feeding Jejunostomy in Esophageal Surgery. Dig Surg 21: 192-196.

25. Doeksen A, Tanis PJ, Vrouenraets BC, Lanschot van JJ, Tets van WF (2007) Factors determining delay in relaparotomy for anastomotic leakage after colorectal resection. World J of GE 13(27): 3721-3725.

26. Rular van o Lame B, Gouma DJ, Reitsma JB Boermeester (2006) Variables associated with positive finding at relaparotomy in patients with secondary peritonitis. Crit Care Med 35(2): 468-476.

27. Martínez-Ordaz JL, Suárez-Moreno RM, Felipez-Aguilar OJ, BlancoBenavides R (2005) Relaparotomy on demand: factors related with mortality. Cir Ciruj 73 (3): 175-178.

28. Martínez-Casas I, Sancho JJ, Nve E, Pons MJ, Membrilla E (2009) Preoperative risk factors for mortality after relaparotomy: analysis of 254 patients. Langenbecks Arch Surg 395(5): 527-534.

29. Katherine Mandell, Saman Arbabi (2010) Re-Laparotomy for Severe Intra-Abdominal Infections. Surg Infect (Larchmt) 11(3): 307-310.

30. Karen Brasel, MD, Morad Hameed, MD, Michael Sarr (2009) Comparison of on-demand and planned relaparotomy for secondary peritonitis. Can J Surg 52(1): 56-58.

31. Seal SL, Kamilya G, Bhattacharyya SK, Mukherji J, Bhattacharyya AR (2007) relaparotomy after cesarean delivery: experience from an Indian teaching hospital. J Obstet Gynaecol Res 33(6): 804-809.

32. Lamme B, Boermeester MA, Reitsma JB, Mahler CW, Obertop H, et al. (2002) Meta-analysis of relaparotomy for secondary peritonitis. Br J Surg 89(12): 1516-1524.

33. VJ werwaal, Academisch Ziekenhuis, St Radboud, Nijmegen (2002) The Netherlands Impact of relaparotomy in patients with abdominal sepsis. Br J Surg 87(7): 946-947.

34. exposito EM, Argon PF, Curbelo PR,Perez AZ (2002) Management of acute peritonitis. Our experience with open abdomen and programmed relaparotomies. Cir Ciruj 70(1): 31-35.

35. Jean-Jacques Duron, Nathalie JS, Sophie Tezenas du Montcel, Anne Berger, Fabrice Muscari, et al. (2006) Adhesive Postoperative Small Bowel Obstruction: Incidence and Risk Factors of Recurrence After Surgical Treatment. Ann Surg 244(5): 750-757. 
36. Brian A Nobie (2009) Obstruction, Small Bowel.

37. Diaa M El-Mowafi, Michael P Diamond (2010) Gynecologic surgery and subsequent bowel obstruction.

38. N Hiki, ' Y Takeshita, K Kubota, E Tsuji, H Yamaguchi, et al. (2003) A seasonal variation in the onset of postoperative adhesive small bowel obstruction is related to changes in the climate, Department of Surgery, The University of Tokyo, Hongo, Bunkyou-Ku, Tokyo, Japan, 113-8655.

39. Elie oussltouzoglou, pillippe bacheliar, Jean marc bigourden, Hiroshi nakano (2004) Pancreaticogastrostomy Decreased Relaparotomy Caused by Pancreatic Fistula After Pancreaticoduodenectomy Compared With Pancreaticojejunostomy. Arch Surg 139(3): 327-335.

40. Ospedale S. Giovanni Bosco (2010) Peritoneal/ Serum Lactate Ratio in Relaparotomy. Clinical Trails.gov

41. Judith Groch (2007) On-Demand Re-laparotomy for Severe Peritonitis Has Benefits.

42. Robert Jasmer, Associate Clinical Professor of Medicine, University of California, San Francisco.

43. HAU T OHMANNC, WOLMERSHAUSER A, WACHA H, QIN YANG, WITTMANN DH, et al. (1995) Archives of surgery ISSN 0004-0010. Surgical Infection Society. Annual meeting N¹5, Louisville KY, ETATSUNIS 130, 1193-1197.
44. Mäkelä J, Kairaluoma MI (1988) Relaparotomy for postoperative intraabdominal sepsis in jaundiced patients. Br J Surg 75(12): 1157-1159.

45. Jonas Dauderys, Donatas Venskutonis (2004) Relaparotomy after abdominal trauma. Vestn Khir Im I I Grek 2(4): 300-307.

46. Novotny AR, Emmanuel K, Hueser N, Knebel C, Kriner M, et al. (2008) Procalcitonin ratio indicates successful surgical treatment of abdominal sepsis. Surgery 145(1): 20-26.

47. Park CE, Sung JE, Kyung MS, Cho Y, Ro ES (2010) A clinical analysis of 10 cases of relaparotomy after emergency postpartum hysterectomy. Korean J Obstet Gynecol 53(4): 313-323.

48. Christian Nordqvist (2007) Repeat Surgery for Peritonitis Patients Better When Clinical Improvement Is Lacking, GastroIntestinal/ Gastroenterology Medical news today.

49. Lombardo Vaillant, Tomás Ariel, Fernandez Exposito, Wilfredo y Casamayor Jaime, Zuleika (2008) Reinterventions in patients with intra abdominal infection. Rev Cub Med Mil [online] 37(4).

50. Martinez Casas I, Sancho JJ, Nve E, Pons MJ, Membrilla E, Grande L (2009).

\section{Your next submission with Juniper Publishers will reach you the below assets}

- Quality Editorial service

- Swift Peer Review

- Reprints availability

- E-prints Service

- Manuscript Podcast for convenient understanding

- Global attainment for your research

- Manuscript accessibility in different formats ( Pdf, E-pub, Full Text, Audio)

- Unceasing customer service

Track the below URL for one-step submission https://juniperpublishers.com/online-submission.php 